\title{
Mainstreaming African Indigenous Epistemologies into Student Development in Higher Education: A Case of Zimbabwe
}

\author{
${ }^{1 *}$ Crispen Mazodze, ${ }^{2}$ Prof. Jacob Mapara, PhD and ${ }^{2}$ Prof. Maria Tsvere, PhD \\ ${ }^{1}$ Bindura University of Science of Science Education \\ ${ }^{2}$ Chinhoyi University of Technology \\ *Corresponding Mail: cmazodze@gmail.com
}

\begin{abstract}
Framed in the context of decoloniality, this study advocates for the embedding of African indigenous epistemologies into student development in university education in order to emancipate it from the pervasive Eurocentric hegemony. The thesis of this paper contends that student development in higher education has remained firmly anchored on Eurocentric ways of knowing at the expense of other epistemologies especially those from the Global South. Indigenous epistemologies are interiorized and marginalized. Efforts to Africanize the curriculum have largely been piecemeal and student development theory has continued to be underpinned by Eurocentric epistemology with a devastating impact on student identity and character development. This study employed the qualitative research paradigm in which three state universities in Zimbabwe were purposively selected as research sites. Data were collected through in-depth interviews with student affairs practitioners and were analysed qualitatively through coding of emerging themes and this was complimented by the use of the NVivo qualitative data analysis software. Results revealed that Eurocentrism is largely the dominant epistemology in student development while African indigenous epistemologies are marginalized, invisibilized and interiorized. The findings also exposed several challenges that are faced by student affairs practitioners with the major ones being; inadequate institutional funding, unavailability of Afrocentric literature on Student Development as well as well as lack of space on the timetable. The study recommended the inclusion of African indigenous epistemologies into student development through the adoption models that imbue cultural values and ways of knowing of indigenous people.
\end{abstract}

Keywords: Student development, epistemology, Eurocentrism, indigenous knowledge, coloniality, decolonization

\section{Introduction}

This study was premised on the context of postcolonial university education in Africa and other countries in the Global South where due to coloniality, indigenous epistemologies, policies and languages are inferiorized, 'othered' and made invisible in student development programming. The term university is in this context used as a collective term to refer to all universities on the continent of Africa as one entity. The study focused on student affairs practitioners in order to determine how and the extent to which they apply a decolonial approach in student development practices. This was achieved through in-depth interviews with student affairs practitioners.

Resonating with this call is the resurgent impetus for the revitalization of indigenous knowledges, cultures and languages as explicated by scholars who have amplified the need to decolonize the university in Africa and free it from Western epistemic and cultural hegemony (Boidin, Sorbonne, Paris, \& Cohen, 2012; Mamdani, 2016; Mampane, Omidire \& Aluko, 2018; Mbembe, 2016; Ndlovu-Gatsheni, 2020; 2018; wa Thiong'o, 1992). Globally, higher education is regarded as a key pillar that spurs the national development because that is where future national leaders and

198 East African Journal of Education and Social Sciences (EAJESS) 2(3)198-210 
policy makers are educated and groomed (Tsvere and Nyaruwata, 2012). However, as OdoraHoppers (2009) aptly observes, the curriculum in most African universities is designed to socialize students on Western culture as a way of making them foundation stones for Eurocentric imperial designs. The current struggles for decolonization in Africa are mainly centered on the epistemological frame, thus making universities battlefronts of the struggle (Ndlovu-Gatsheni; $2018,2020)$. The decoloniality movement is quite equivocal on its fight for the decolonization of institutions of higher learning with particular focus on knowledge production and reproduction, the disciplines, pedagogy and institutional culture.

Though various forms of decolonizing the university have been proffered, no serious effort has been made to interrogate student development and the need to decolonize its epistemology. Therefore, this study predicated on the call to decolonize student development in universities, attempts to fill in this gap. According to Ndlovu-Gatsheni (2020; 2021), colonialism did not end with the attainment of political independence from European imperial powers, but it resurrected itself through a system called coloniality. He describes coloniality as epistemic domination which exhibits itself in the form of Eurocentric hegemony over culture, languages as well as knowledge production and validation. Due to coloniality, this study identified student development as space that needs to be decolonized owing to the over-representation of Eurocentric epistemologies and the absence of African indigenous ways of knowing. NonEurocentric epistemologies have been silenced and treated as the other which is inferior and not worth of recognition.

\section{Student Development in Higher Education}

To contextualize the impact of coloniality on student development in African higher education, it is worthwhile to provide a brief outline of its origin, scope and function. Student Development has been defined as the level of engagement that students devote to college experiences within curricular and co-curricular activities (Tinto, 2017). The focus of SD is on planning programs and activities that are aimed at facilitating students to acquire values that will shape their adult lives, their development of a stable identity, moral and spiritual values, leadership and interpersonal skills (Astin, 2005; Long, 2012). Some studies indicate that the purpose of student development in higher education is to develop students' psycho-motor and affective skills as well as fostering leadership transformation and cultural consciousness (Astin, 2005; Magolda and Astin, 1993; Tinto, 2017). In the African higher education context, studies indicate that student development is a growing practice with special focus on psycho-social, identity and leadership development (Adjei and Amoako, 2021).

Universities in most sub-Saharan African countries were introduced as direct imports from higher education in the colonial power. Therefore, university structures, the disciplines and co-curricular activities were designed using templates from the west and for some time these universities were affiliated to universities in Britain, France, Portugal and the United States of America. The co-curricular activities are structured and coordinated in a similar fashion by the Student Affairs departments. Higher education was introduced to train African elites who would assist in colonial administration. Hence the academic and co-curriculum were designed to promote Western civilization at the expense of African culture and indigenous knowledges (Mandew, 2003). African indigenous epistemologies, languages and subjectivities were heathenized, interiorized, peripherised and in extreme instances, 'invisibilised.' This resulted in the death of African cultures, epistemologies, values and identities.

This tendency has continued after the gaining of political independence due to coloniality. Culture is the carrier of a people's moral, ethical and aesthetic values while values are the embodiment of a people's consciousness as a community (wa Thiong'o, 1993; Mapara, 2009). Therefore, Student Development in higher education must be decolonized because in its current form, it has become a site that reproduces Eurocentric identities and subjectivities. Decolonization of Student Development denotes the inclusion of indigenous African epistemologies, cultures and languages in its programming.

\section{Theoretical Framework}

This study is based on the premise that despite attempts of Africanizing higher education 
curriculum by postcolonial African countries in order to make it relevant to the needs of local communities, the hegemonic influence of Eurocentrism has remained entrenched (Oppong, 2013). Eurocentrism views the world from a Euro-American lens that advantages Western epistemologies and values while demeaning African ones. It is on the basis of this consideration that this study adopted decoloniality as an appropriate tool to reverse this sad scenario.

The theory underpinning this study is informed by the scholarly works of Quijano, MaldonadoTorres, Mignolo, Grosfoguel, Smith, wa Thiong'o, Ndlovu-Gatsheni and other intellectuals who have conjectured on the theory of decoloniality. In addition, the works of Odora-Hoppers, Nabudere and Mungwini who have theorised on the notions of cognitive justice and epistemic injustice in knowledge construction and validation have also enlightened the discussion of this study. Decoloniality aims to decolonize knowledge production and revitalize the epistemologies of the Global South as the epicenters of knowledge generation in higher education. While decoloniality focuses on emancipating Africa from Western epistemological and ontological hegemony, it does not render it to the denunciation of Eurocentric ways of knowing but it rests on repositioning indigenous African knowledges to be considered on equal terms with Eurocentrism.

In the quest to seek a conceptual understanding of decolonial theory, it is imperative to first comprehend the impact of colonization and the pervasive on-going coloniality on student development. It is a reality that despite gaining political independence several decades ago, African states are trapped in a coloniality of power, knowledge and being nexus which extends to economic, cultural, linguistic and epistemological imposition by the West (Grosfoguel, 2013; Mignolo, 2013; MaldonadoTorres, 2019). Decoloniality has, as a result, emerged in response to the hegemonic dominance of the Euro-American conceptualization of modernity that justifies coloniality (Ndlovu-Gatsheni, 2018; 2020).

Coloniality continues to thwart decolonial initiatives aimed at loosening the grip of the West on knowledge production and validation in the Global South. This shows that the struggle for epistemic freedom from Western domination is far from being achieved. For genuine independence to occur, there is need for the global South to delink from the exploitative and oppressive West leading to total political, economic and onto-epistemological freedom (Ndlovu-Gatsheni, 2013, 2015, 2018, 2020).This control persisted through what decolonial theorists refer to as coloniality of power, knowledge and being (Maldonado-Torres, 2016). Within this scope, the concept coloniality of knowledge critically interrogates the epistemicides that facilitated the dominance of Eurocentric epistemologies leading to the colonization of African minds.

Coloniality of being is used to reveal the complex processes of subjectivity that were employed to create inferiority complexes in the psyche of Africans (Maldonado-Torres, 2019). The researchers concur with Maldonado-Torres (2016, 2019) and argue that through the formal and informal curriculum, academics and Student Development practitioners have been mentally colonized to the extent that they have become the gate keepers of coloniality. To remedy the situation, there is need for academics and Student Developers to develop Student Development models that imbue indigenous knowledges and shift from being mere consumers of Western theories and models.

One may ask how the university and in particular Student Development is involved in maintaining this Eurocentric coloniality of power matrix? The university from its original historical function has remained largely to produce elites and now its duty in the globalized neo-liberal world is focused on the production of transnational elites (SuárezKrabbe, 2012). In this perspective, Castro-Gomez cited in Suarrez-Krabbe (2012, p. 35) describes the university as "the triangular structure of coloniality of power, knowledge and being." This denotes that the university in sub-Saharan Africa continues to be the vital link through which coloniality is maintained in countries such as Zimbabwe. In the context of higher education in Zimbabwe, the ways in which the university operates in the service of global coloniality are overt and varied.

The university is an epistemic site of contestation that needs to be decolonized because of the absence of indigenous ways of knowing and the 
over-representation of Eurocentrism in the production of and validation of Student Development knowledge (Mbembe, 2016; Magoqwana, 2018; Ndlovu-Gatsheni, 2018). Epistemic freedom will bring to finality the unfinished business of decolonization by granting Africans the right to think and conjecture on equal foothold with the West, leading to the creation of a new civilization where there is coexistence of knowledges (Ndlovu-Gatsheni, 2021). From the Zimbabwean academic terrain, calls to include indigenous knowledges into the curriculum are growing louder (Mapara, 2017). The Zimbabwean ministry of higher education has also added its voice on the discourse by advocating for embracing cultural heritage for tertiary and higher education in Zimbabwe. Therefore, this study is not an isolated academic endeavor, but one which is intended to contribute to the decoloniality narrative and debate by extending the discourse to include Student Development and also contribute to knowledge building by developing a student leadership frame that is anchored on hunhu/ubuntu philosophy.

As explained earlier, the contemporary university in Africa has faced criticism of having been birthed out of a neo-liberal tradition that suppressed indigenous epistemologies in the academy as well as in the co and extra-curricular activities. Literature on decolonizing the university so far has not included research focusing on whether decolonial strategies have been adopted by Student Affairs practitioners and how this inclusion or exclusion is impacting on graduates' affective attributes. Decolonizing the African university implies challenging Eurocentric epistemologies with the aim of creating an ecological co-existence between African and Eurocentric ways of knowing (Ndlovu-Gatsheni, 2018). From this ecological integration of epistemologies, there emerges a new transformative frame and praxis in curricular and co-curricular student leadership development programs.

The university from its original historical function has remained largely to produce elites and now its duty in the globalized neo-liberal world is focused on the production of transnational elites (Suárez-Krabbe, 2012). In this perspective, Castro-Gomez cited in Suarrez-Krabbe (2012, p. 35) describes the university as "the triangular structure of coloniality of power, knowledge and being." This denotes that the university in subSaharan Africa continues to be the vital link through which coloniality is maintained.

In relation to this study, coloniality of power also looks into the psycho-social dimensions of student development where Eurocentrism exerted its destructive influence on epistemic, ontological and axiological domains of Student Development. It is seen through mental colonization or cognitive domination which is expressed through racist dehumanization, objectification and inferiorisation of Africans as portrayed in textbooks, films and co-curricular activities. Most of these productions which are cultural goods are given as donations to colleges and universities in sub-Saharan Africa. This development has resulted in African students shunning their blackness by using skin lightening creams to appear as whites as exemplified by the terms 'salads', 'nose brigades' and 'yellow bones'. In Southern African countries, female students who lighten their skins are known as 'yellow bones' (Makobela, 2017). Studies have shown that in black communities, a woman with a lighter complexion i.e. a yellow bone, is privileged with a higher social status than one with a darker skin (Makobela, 2017). Due to this idealization, African female youths strive to achieve this 'yellow bone' status often with disastrous consequences because some skin lighteners damage their skin. Ndlovu-Gatsheni (2013) exposits that the quest by African youths to ape whiteness indicates that Europeans succeeded in implanting negative images about blackness by modelling Europeanization into an aspiration for most African youths.

Ndlovu-Gatsheni (2015, p. 194) observes that,

... the long term effect of this social engineering and epistemological process that was marked by epistemicides that invaded the core imaginary of the African psyche and culture to the extent that Africans today produce cultural Europeanization without direct tutelage of Europeans.

The psycho-social and epistemological damage that was done is quite deep and the challenge that faces African theorists and indeed Student Development practitioners is how to inverse this mental impairment. At the cultural and 
epistemological level, most Africans are still stuck in Eurocentric thought and they daily breathe coloniality. To remedy this situation, the researchers concur with Mignolo (2013) who advocates for epistemic delinking from the West leading to the upliftment of indigenous epistemologies as new sites of knowledge production in the Global South.

The point of departure of the decolonial theorists is that different human societies produce different forms of observing the world. As such, Student Development theoretical design requires more than Eurocentric epistemologies. This implies that Student Development models based on Western knowledge systems cannot claim universal applicability because they are partial, situational and incomplete. From this perspective, pluriversalism denotes that African indigenous epistemologies can no longer be considered as inferior, uncivilised and not pat of the canon of thought.

The analysis outlined above exposes Student Development as being tied to the project of reproducing the matrix of coloniality, not only through the reproduction of particular orientations, biases and preferences among students but also a question of the compulsive reiteration of the ethical and epistemological order of Eurocentrism. In line with the decolonial project advocated by theorists such as Dussel, Mignolo, Maldonado-Torres, Grosfoguel, Santos and Ndlovu-Gatsheni, to mention just a few, this study articulates the need to reinvigorate African indigenous epistemologies in order to decolonise the structure of knowledge in the Westernised universities. Within this spectrum, decolonilaity means breaking with the current scenario where Western epistemology defines the rest of the world. Decolonisation of the curriculum entails the foregrounding of indigenous epistemologies into the students' learning experiences which have been dominated by Eurocentrism for centuries (Ndlovu-Gatsheni, 2020). This denotes bringing epistemic diversity into Student Development theory making so as to create a pluriverse of meaning and concepts in student development in Sub-Saharan Africa higher education. This theoretical framework provided a sound philosophical ground for answering the following research questions which guided this study:
1. How do student affairs practitioners in Zimbabwean universities embed indigenous ways of knowing into Student Development?

2. What are the challenges faced by srudent affairs practitioers in embedding indigenous epistemologies into Student Development?

\section{Research Methodology}

This study was intended to explore Student Development which is a complex phenomenon that stimulates the production of thick description and textured explanations. Therefore, qualitative research strategies were considered best for the research. Qualitative research methods allow for inductive and naturalistic interpretations (Cohen, Manion and Morrison, 2007; Creswell and Creswell, 2018). In an effort to amplify this method, grounded theory was considered the ideal methodology to gather, analyze and interpret data because of its ability to unpack how complex phenomena occur (Charmaz, 2017; Leavy, 2017; Lewis, 2015). The choice of grounded theory among a plethora of other methods was not arbitrarily done, but was carefully arrived at after satisfying the researchers that it fits well with the interpretivist nature of this study.

Charmaz (2017) contends that grounded theory assumes the researcher to be connected to the phenomena being studied. In this vein, one of the researchers is a student affairs practitioner at one of the state universities in Zimbabwe, hence grounded theory was quite ideal to this study since the researcher would utilise personal proximity as an opportunity to shed more light on the area under investigation. The researchers had aimed at developing a student development model that imbues indigenous knowledge and the prevailing Eurocentric models to assist student affairs practitioners in embedding indigenous epistemologies. Therefore, grounded theory was deemed fit for this purpose because of its capacity to explore a process with the aim of developing a theory (Creswell, 2009; Creswell and Creswell, 2018). In relation to this study, grounded theory aided the discovery of key attributes that provided a framework that was used to develop the Three-Legged Pot model that infuses ubuntu values. 


\section{Population and Sampling}

The study was conducted at three state universities in Zimbabwe namely, Bindura University of Science Education (BUSE), Chinhoyi University of Technology (CUT) and Great Zimbabwe University (GZU) which were purposively chosen basing on the fact that they shared similar structures of student affairs management. Further, the universities share a similar foundation in that they were set up almost at the same time and through a similar process. The population consisted of student affairs practitioners (SAPs) who were directly involved in Student Development programming and implementation. A total of twelve SAPs who included Deans of students, Coordinators of Campus life and student development, Counsellors and Wardens were purposively selected as the sample of the study on the basis of their knowledge of the subject of the study (Creswell and Creswell, 2018). The participants were coded as $A, B, C$ up to $L$ to protect their identity. A snowballing sampling technique in which a sample is gradually formed through contacts and references was also used to compliment purposive sampling in coming up with the sample for the study.

\section{Validity and Reliability}

Guba and Lincoln cited in Creswell and Creswell (2018) note that under qualitative research paradigm, the terms used to refer to validity and reliability are credibility, dependability, transferability and confirmability. The researchers ensured that these important indicators of validity and reliability were safeguarded through the processes of member checking, persistent observation and de-briefing. The researchers engaged each of the participants in discussion to ascertain that their responses were accurately captured, thus ensuring credibility and dependability of the results.

\section{Data Collection and Analysis}

In-depth interviews were used to collect data using semi-structured questions to keep the researcher and participants on track of the important themes of the study. Interviews were recorded and field notes were taken during the interviewing process, while emerging themes were being coded at the same time. Data was analysed through thematic analysis which involved elaboration and interpretation of coded data (Creswell and Creswell, 2018). This was complimented with the use of NVivo qualitative data analysis software.

\section{Ethical Considerations}

The researchers ensured that before commencement of data collection, ethical approval was granted by the authorities at the universities under investigation to gain access to and acceptance by the participants. Further, the researchers sought individual informed consent and voluntary participation with each of the participants. Participants were guaranteed anonymity, confidentiality and protection by ensuring that their identities were not revealed. The researchers used codes to identify participants and not their actual names as recommended by Cohen, Manion and Morrison (2007). This enlisted honest and frank responses from the participants. Further, non-malfeasance is a key ethical principle which the researchers strictly adhered to throughout the entire data gathering process.

\section{Results and Discussion}

In an attempt to aswer the research questions, the study sought to ivestigate whether SAPs were engaging in decolonial approaches by incorporating African indigenous epistemologies in the designing of Student Development programs.

Research Question 1: How do student affairs practitioners in Zimbabwean universities embed indigenous ways of knowing into Student Development?

The first research question concerns the SAPs' engagement with non-Eurocentric knowledge. In analyzing data, the researchers considered the recognition of the absence of African indigenous epistemology as being key to data analysis and interpretation. This helped to avoid approaches that lead to epistemicides and culturecides as a result of the subalternisation of non- Eurocentric epistemologies. The researchers asked whether the absence of African indigenous knowledges and policies in Student Development was being addressed. The responses of the SAPs to this question demonstrated that the influence of Eurocentric epistemology was central in Student Development models. Participant A, for instance, explained that:

Yes we also emphasize the need for our students to have hunhu/ubuntu values. 
However, it is clear that the use of western models and language shows that the space for indigenous knowledge in our activities is very small. Our campus culture is elitist and students from rural backgrounds initially struggle to fit in.

This view was supported by participant $C$ who indicated that "The theories we use in SD are Western so the room for indigenous knowledge is very small and informal." Participant $F$ concurred explaining that "There is some room for the inclusion of indigenous models despite the fact that our universities are based on European model that instils European values. It also depends on the philosophical interests of the practitioner."

These three participants explicitly confirmed that they contrived to present Student Development programs that incorporated both Eurocentric and African indigenous ways of knowing. However, on further interrogation, it was revealed that these epistemologies were not treated on equal terms since Eurocentrism had a larger percentage of material because as Participant $C$ pointed out, it was regarded as the 'foundational epistemology of Student Development theory.

Most of the SAPs indicated that they were not trained on decolonization, hence their overdependence on Western theories and literature. Participant $\mathrm{K}$ summed up this position thus;

My training oriented me to depend on content in textbooks ... and most of the textbooks and documents on Student Development originate from the West -I am not aware of the existence of theories that are informed by African indigenous knowledge.

The findings also revealed the huge influence of corporates and NGOs on Student Development due to lack of institutional funding. It is important to note that these organizations are neo-liberal in outlook; hence they only fund programs that promote their ideology. This further promotes the marginalization of African indigenous epistemologies in Student Development programming. Participant E summed up this position, pointing out that:

We work with such organisations as Star Leadership funded by large corporates, Boost-Enactus and SAYWHAT an NGO --- these provide funding of some of the Student Development programmes not only at this university but in almost all universities in Zimbabwe. Most of the documents that they provide are Eurocentric. Our hands are tied because they provide a lot of funding of the Student Development activities on campus. If we go against them, we could loose their funding at a time when institutional funding of Student Development is drying up.

The findings revealed that coloniality of power, knowledge and being was pervasive in Student Development theory and practice with a devastating impact on students' identity development. The existing Western template of Student Development socializes students into Eurocentric identities, leading to students imitating Western hairstyles, speech tones and skin complexion. This perspective was further expressed by Participant A, who indicated that;

The impact of Eurocentrism on student identity development is that students end up shunning their Africanness, they consider it being inferior. Indigenous cultural values end up being ended. This is seen when female students use skin lightening pills and creams to imitate being white and we call them yellow bones. They also try to imitate white hairstyles. Male students would strive to speak through their nose imitating Western speech tones. Those who cannot catch up with these speech tones, skin color and hairstyles are derisively regarded as SRB- i.e. those with strong rural background.

The findings demonstrated that Eurocentric theories formed the core of Student Development epistemology. This pointed to the hierarchisation of knowledges informing Student Development theory with non-Eurocentric ways of knowing being marginalized. This shows that Student Development is laden with a heavy baggage of coloniality, hence there is need to decolonize it by imbuing African indigenous knowledges and policies.

Student development pedagogy has been used as tool for epistemic domination, particularly the clubs such as Debate and Toastmasters which 
promote the supremacy of British middle-class culture and the English language. The study findings show that this results in culturecides, linguicides and identicide. The findings show that
Eurocentric social identities are prevailing in Student Development programs as evidenced by the thriving campus sub-culture of yellow bones, salads and nose brigades as indicated in Figure 1.

\section{Text Search Query - Results Preview}

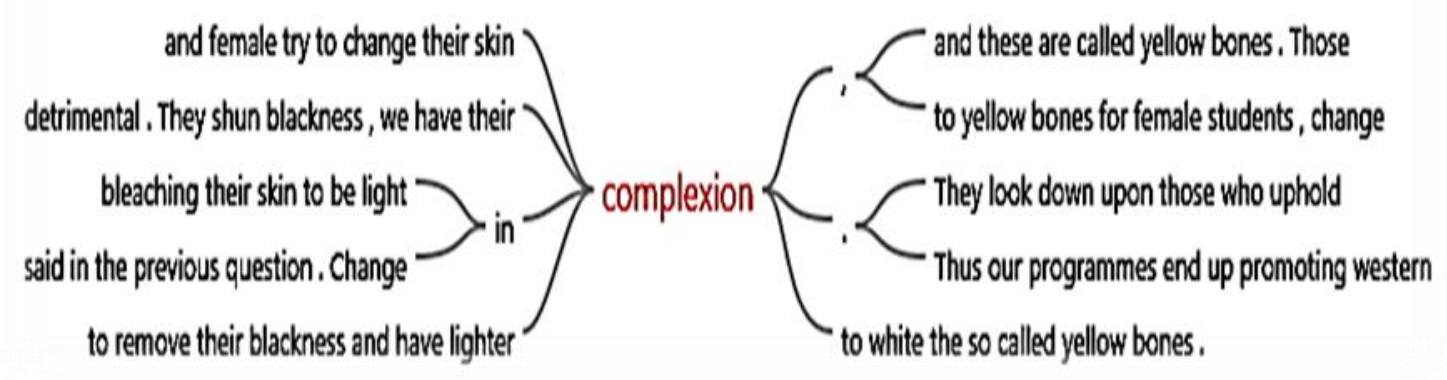

Figure 1: Text Search Query- Results Preview

Research Question 2: What are the challenges faced by srudent affairs practitioers in embedding indigenous epistemologies into SD?

The findings also indicated that SAPs faced a myriad of challenges which stifled their efforts to include indigenous epistemologies into student development practice. It emerged that lack of time negatively impacted student development programming since the timetable was congested with academic curricula activities. Participant $G$ explicitly summed up the position indicating that;

Student development programs are not given enough recognition. Therefore, they are not catered for on the timetable. So, we are forced to do student development programs after hours. Students will be tired and some who stay out of campus would have left campus.

Lack funding was also cited as a major challenge hindering the process of embedding indigenous African epistemologies into Student Development. This view was supported by participant $\mathrm{D}$ who stated that:

Student Development is not seriously regarded, hence funding is just too little. Further, SD is not timetabled; therefore programs are not usually budgeted for. So, we end up depending on external partners e.g. Banks, Corporates and NGOs who fund some club activities. This is good but it takes away our power to decide which programs they should fund as they come with their own agendas. Their literature is Eurocentric and they strive to produce leaders who are programmed to support Eurocentric views and perspectives.

The findings also indicate that the marginalization of the indigenous languages was a major stumbling block that hindered the SAPs in their efforts to decolonize Student Development practice. Participant B was very categorical on the impact of marginalization of indigenous languages in Student Development indicating that:

The language that we use in SD is English. It is practically the official language at this University. Our indigenous languages suffer and students also look down upon those who can't speak English fluently with nasal tones. Language is the carrier of indigenous values and if we do not promote our languages, they will end up being neglected.

The study revealed that Eurocentric epistemologies were dominant in Student Development theory while African indigenous ways of knowing were marginalized. The hegemony of Eurocentric epistemologies in Student Development theory has created a situation where cultural and identity consciousness, leadership training and the acquisition of critical life skills tend to be 
conceptualized from a Eurocentric lens. This approach diminishes opportunities for the incorporation of African indigenous epistemologies into Student Development theory and praxis. The study also revealed the challenges that hinder the embedding of African knowledges, values and languages into Student Development which included lack of Afrocentric literature on Student Development theory and poor funding of student development programs by universities. In synthesizing the findings, the researchers present a model on Student Development that is anchored on hunhu/ubuntu epistemology.

This study explored the embedding of African indigenous ways of knowing, values, cultures and languages into Student Development. The hegemony of Eurocentric epistemologies in SD theory has created a situation where cultural and identity consciousness, leadership training and the acquisition of critical life skill tend to be conceptualized from a Eurocentric lens. This approach diminishes opportunities for the incorporation of African indigenous epistemologies into Student Development theory and praxis. To reverse this process, this research amplifies calls for the reinvigoration of efforts to mainstream indigenous knowledges into Student Development by reclaiming hunhu/ubuntu values into SD epistemology. Theorizing on this complexity, the study identified mainstreaming hunhu/ubuntu values as a practical approach to address these effects of onto-epistemological coloniality. Thus, the researchers came up with the Three-Legged Pot model that imbues hunhu/ubuntu values. Hunhu/ubuntu is the philosophy that shapes the ontology and epistemology of the Bantu people of Zimbabwe and other Sub-Saharan African countries and it is considered to be the foundation of a person's identity among these indigenous people.

According to Mapara (2013) hunhu/ubuntu is a moral ethic whose values are passed from one generation to the other through socialization and enculturation first by the family and by community members. Hunhu/ubuntu is a set of beliefs and values that guide the manner in which a person conducts him or herself in relation to other people and the environment (Gade, 2011; Madambi and Mangena, 2016; Malunga, 2006; Mapara, 2013; Metz, 2014). It engenders an ethos that influences the peoples' day to day way of life and shapes their behavioral patterns and sets the bounds on which a person can be qualified as being human. Therefore, hunhu/ubuntu forms the essence of personhood that is gained and maintained through the person's communally acceptable actions and social relations. Thus, the individual and the community are entwined and a person's identity is conjoined with that of the society.

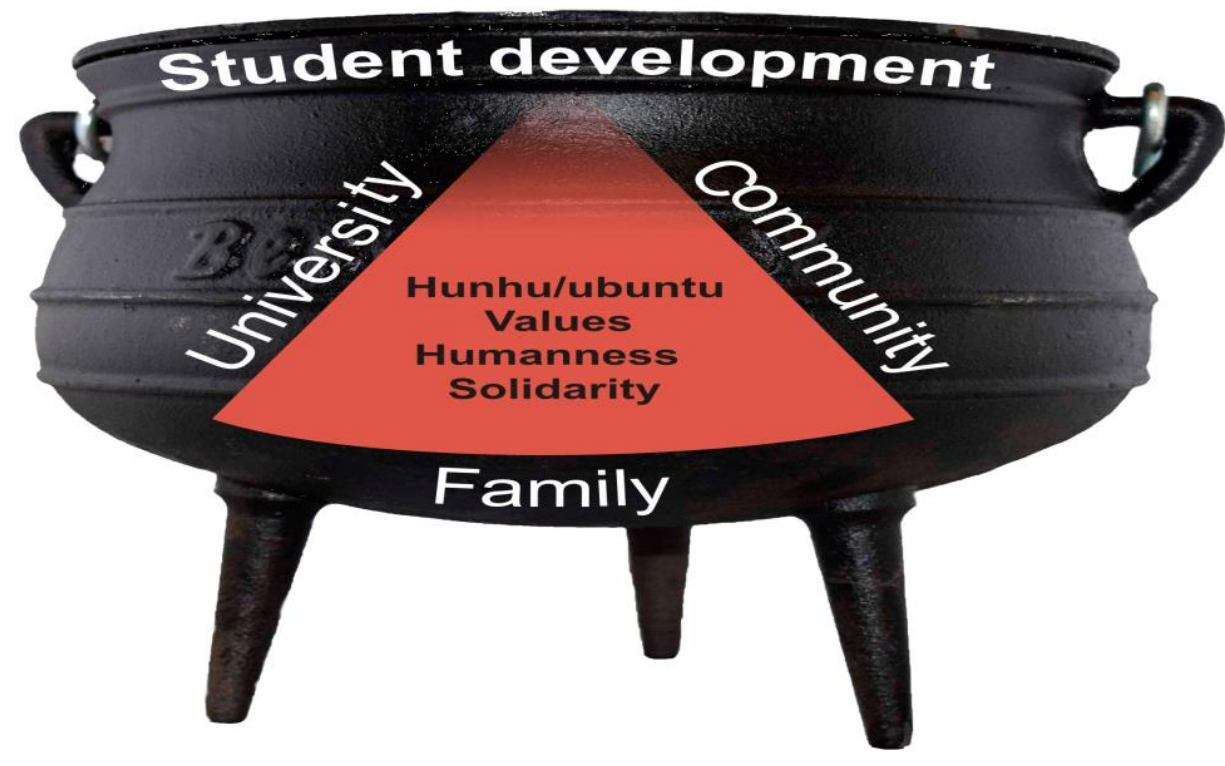

The model resembles a three-legged pot which is usually found at each household in a traditional African family in Zimbabwe. The pot is big enough to feed a large gathering and would usually be used on family gatherings or village functions such as nhimbe (co-operative work 
village gatherings) or funerals. At such functions, family members or villagers bring some food item that will be cooked and shared amongst those present. It symbolizes solidarity, humanness and cohesion in the family or at village level. The pot rests on three legs for balance and as a sign of wholeness. It cannot stand on one or two legs as it would lose its balance and collapse and no cooking would take place. The three-legged pot symbol resonates well with the Social Enculturation/Three-Legged Pot model which advocates for three pillars of student enculturation, growth and maturation to work together to achieve a holistic student development. Holinism calls for the acknowledgement that traditional African epistemologies are valid and reliable sources of knowledge (Sefa Dei, 2013).

The model advocates for collaboration among the three pillars of student enculturation and learning namely the family, the community and the university. Just as the pot cannot stand on one or two legs, the university cannot successfully produce holistic graduates on its own with the co-operation of the other two. Holistic development implies completeness and well-rounded growth and maturation. This cannot be attained under the current scenario where the university and corporates take center stage while the parents and the community where students come from are marginalized. It would be like the three-legged pot is standing on one and half legs. There is no balance and the pot will collapse and in the case of student development its goals will not be attained since the other pillars and their values and knowledges are marginalized and silenced.

This model is anchored on hunhu/ubuntu a Bantu epistemology of human development which is passed on to members of society through active enculturation and socialization. In the traditional Bantu society, the family and society were central transmitters of values and identity development consciousness. There were no formal schools and the young learnt through observing and participating in family and communal activities under the mentorship of elders in the family and community. Such active participation and observation molded the young into a well-rounded munhu/umuntu or person with hunhu/ubuntu values. A person acculturated and socialized with hunhu/ubuntu values was well-rounded, respectable and an upright person.

This model is relevant to student development practice in Sub-Saharan African countries because it imbues hunhu/ubuntu epistemology which has stood the test of time as it has survived the onslaught of Eurocentrism against indigenous cultures and knowledges. The model is responsive to the context of the local indigenous people as well as to the global imperatives and its use would result in the production of well-rounded graduates who are grounded in their indigenous as well as global ways of knowing.

The Social Enculturation/Three-Legged pot model enables a clear expression of indigenous epistemologies in student development programming through the embodiment of indigenous languages, stories and cultural practices that can be expressed through drama, poetry, song and dance. While the model gives prominence to the marginalized experiences and ways of knowing of indigenous people, it also acknowledges that students live in a polyepistemic global environment. It does not advocate for a return to pre-colonial lifestyles and cultural environment but it calls for the recognition of the important role that indigenous African epistemologies, values and languages play to the achievement of sustainable community development.

\section{Conclusions and Recommendations}

This study was grounded on two research questions, with the first one asking whether student affairs practitioners were embedding African indigenous epistemologies into student development while the other one was designed to expose the challenges faced by student affairs practitioners in their decolonial efforts. The findings revealed the dominance of Eurocentric epistemologies in student development theories. The study further demonstrated that the marginalization of the indigenous epistemologies resulted in campus sub-cultures in which the youths looked down upon their black identity, their languages and cultural values.

This paper further concludes that student affairs practitioners faced several challenges, the major ones being inadequate institutional funding and lack of space on the timetable as well as the absence of Afrocentric literature on Student 
Development. These challenges were cited as stumbling blocks that impeded the mainstreaming of African indigenous epistemologies into Student Development.

Based on the findings of this study, the researchers recommend development of a policy framework to guide SD programming in higher education. They also recommend prioritization of African indigenous cultural values such as hunhu/ubuntu and indigenous languages in the implementation of Student Development programs. Furthermore, there is a need to involve parents and local communities in Student Development activities.

\section{References}

Adjei, M., Pels, N. A., \& Amoako, V. N. D. (2021). Reflective practice Responding to Covid 19: Experiences of Ashesi University's Student Affairs Team. 9(1), 0-3. https://doi.org/10.24085/jsaa.v9i1.1433

Astin, A. W. (2005). How College AffectsStudents. Volume 2: A Third Decade of Research (review). The Review of Higher Education, 29(1), 120-122. https://doi.org /10. 135 3/rhe.2005.0057.

Boidin, C., Sorbonne, U., Paris, N., \& Cohen, J. (2012). Introduction : From University to Pluriversity: A Decolonial Approach to the Present Crisis of Western Universities A Decolonial Approach to the Present Crisis of. Human Architecture:Journal of the Sociology of Self-Knowledge, 10(1), $1-7$.

Charmaz, K. (2017). The Power of Constructivist Grounded Theory for Critical Inquiry The Power of Constructivist Grounded Theory for Critical Inquiry. March 2016. https://doi.org/10.1177/1077800416657 105.

Cohen, L., Manion. L., \& Morrison, K. (2007). Resaerch nMethods in Education (Vol. 55, Issue 4). https://doi.org/10.1111/j.14678527.2007.00388_4.

Cresswell, J. W. (2009). Research Design: Qualitative, Quantitative and Mixed Methods Approaches (3rd Edition). SAGE.
Creswell, J.W., \& Creswell, J.D., (2018) Research Design: Qualitative, Quantitative and

Mixed Methods Approaches, Los Angeles: Sage.

Gade, C. B. N. (2011). The historical development of the written discourses on ubuntu. South African Journal of Philosophy, 30(3), 303-329. https://doi.org/10.4 314/sajp em.v30i3.69578.

Grosfoguel, R. (2013). The Structure of Knowledge in Westernized Universities: Epistemic Racism / Sexism and the Four Genocides / Epistemicides of the Long 16th Century. 11(1).

Leavy, P., (2017). Resaerch Design: Quantitative, Qualitative, Mixed Methods Arts-Based and Community-Based Participatory Research Approaches, New York : The Guilford Press

Lewis, S. (2015). Qualitative Inquiry and Research Design: Choosing Among Five Approaches. In Health Promotion Practice 16(4). https://do i.org/1 $0.1177 / 1524839915580941$.

Long, D. (2012). The foundations of student affairs: A guide to the profession. Environments for Student Growth and Development: Librarians and Student Affairs in Collaboration, 1-39.

Madambi, M., \& Mangena, F. (2016). University of Zimbabwe and the Struggle for Humanising Philosophy: 1980 to Present. Journal of Pan African Studies, 9(2), 116.

Magolda, M. B. B., \& Astin, A. W. (1993). What "Doesn't" Matter in College?What Matters in College: Four Critical Years Revisited. Educational Researcher, 22(8), 32. https://doi.org/10.2307/1176821.

Magoqwana, B. (2018). "Putting Food Back on the Table": Decolonising Towards a Sustainable University that Feeds Us in South Africa. International Journal of African Renaissance Studies, 13(2), 112128. https://doi.org/10.1080/1818 6874 .2018.1536421. 
Makobela, T. (2017). Perceptions of Black Men in Katlehong about Female "Yellow Bones ": A Case Study. 0002(August).

Maldonado-Torres, N. (2016). Outline of Ten Theses on Coloniality and Decoloniality. Frantz Fanon Foundation, 1-37.

Maldonado-Torres, N. (2019). Nelson Maldonado-Torres, "Frantz Fanon, Decoloniality, and the Spirit of Bandung,." Journal of Global World Literature, 13, 236-252.

Malunga, C. (2006). Learning Leadership Development from African Cultures: from African Cultures : INTRAC Praxis 25, 25, 1-14.

Mamdani, M. (2016). Inter-Asia Cultural Studies Between the public intellectual and the scholar: decolonization and some postindependence initiatives in African higher education. 9373. https://doi.org/10 $.1080 / 146493$ 73.2016.1140260.

Mampane, R. M., Omidire, M. F., \& Aluko, F. R. (2018). Decolonising higher education in Africa: Arriving at a glocal solution. South African Journal of Education, 38(4). https://doi.org/10.15700/saje.v38n4a16 36.

Mandew, M. (2003). A Guide to Student Services in South Africa, Pretoria. CHET.

Mapara. J. (2013). Ngano: A Platform for the dissemination of Ubuntu/Unhu values. In J. \& Mapara \& B. Mudzanire (Eds.), Ubuntu/Unhu Philosophy: A Brief Shona Perspective (pp. 99-124). Bhabhu Books.

Mapara, J. (2009). Indigenous Knowledge Systems in Zimbabwe: Juxtaposing Postcolonial Theory. Journal of Pan African Studies, 3(1), 139.

Mapara, J. (2017). Binarism as a recipe for lukewarm research into indigenous knowledge systems in Zimbabwe. Handbook of Research on Theoretical Perspectives on Indigenous Knowledge Systems in Developing Countries, 1-21. https://doi.org/10.4018/978-1-52250833 -5.ch001.
Mbembe, A. (2016). Decolonizing the university: New directions. Arts and Humanities in Higher Education, 15(1), 29-45. https://doi.org/10.1177/1474022215618 513.

Metz, T. (2014). Just the beginning for ubuntu: Reply to Matolino and Kwindingwi. South African Journal of Philosophy, 33(1), 65https://doi.org/10.1080/02580136.20 14.892680 .

Mignolo, W. (2013). Geopolitics of sensing and knowing: On (de)coloniality, border thinking, and epistemic disobedience. 1(1), 129- 15https://doi.org/10.338 4/con fero.2001-4562.13v1i1129.

Ndlovu-Gatsheni, Sabelo J. (2013). Coloniality of power in postcolonial Africa: Myths of decolonization. Coloniality of Power in Postcolonial Africa: Myths of Decolonization, 1-293.

Ndlovu-Gatsheni, Sabelo J. (2015). Global Coloniality and the Challenges of Creating African Futures. Strategic Review for Southern Africa, 36(2), 181202.

Ndlovu-Gatsheni, Sabelo J. (2018). Epistemic Freedom in Africa:Deprovincialisation and Decolonisation. London: Routledge.

Ndlovu-Gatsheni, S.J. (2020). Decolonisation, Development and Knowledge in Africa: Turning a New Leaf. London: Routledge.

Ndlovu-Gatsheni, Sabelo J. (2021). Why has Europe's Past become Africa's Postcolonial Present? Reflections on Mahmood Mamdani's ideas on decolonising the Political Community. CODESIRIA Bulleti Online, 12(2-3), 1-7. https://doi.org/10.1016/s0167-0115( 01 )00338-x

Odora Hoppers, C. A. (2009). Education, culture and society in a globalizing world: Implications for comparative and international education. Compare, 39(5), 601-614.

Oppong, S. (2013). Indigenizing Knowledge for 
Development: Epistemological and Pedagogical Approaches. Africanus: Journal of Development Studies, 43(2), 34-50.

Sefa Dei, G. J. (2013). Indigenising The Curriculum:The Case of The African University. In African Indigenous Knowledge And the Disciplines. Sense Publishers.

Suárez-Krabbe, J. (2012). 'Epistemic Coyotismo' and Transnational Collaboration: Decolonizing the Danish University Decolonizing the Danish University. 10(1).
Tinto, V. (2017). Through the Eyes of Students. Journal of College Student Retention: Research, Theory and Practice, 19(3), 25426https://doi.org/10.1177/15210251 15621917.

Tsvere, M. \& Nyaruwata (2012). Gender mainstreaming in higher education: Experiences from Africa. Zimbabwe International Journal of Open and Distance Learning, 2000, 87-93.

wa Thiong'o, N. (1992). Moving the centre: the struggle for cultural freedoms. In Studies in African literature. https://d oi.org/ $10.1177 / 002198949102600116$. 